\title{
CIRCULAR ECONOMY AND INNOVATION: A SYSTEMATIC LITERATURE REVIEW
}

\author{
Herrero-Luna, S., Ferrer-Serrano, M., Latorre-Martinez, M. P.
}

Sonia Herrero-Luna / University of Zaragoza, Faculty of Business and Economics, Department of Business Management, Paseo de la Gran Vía, 2, 50005, Zaragoza, Spain. Email: 739193@unizar.es

Marta Ferrer-Serrano / University of Zaragoza, Faculty of Business and Economics, Department of Business Management, Gran Vía, 2, 50005, Zaragoza, Spain. Email: martafe@unizar.es

María Pilar Latorre-Martínez / University of Zaragoza, Faculty of Social Sciences and Work, Department of Business Management, C/ Violante de Hungría, 23, 50009, Zaragoza, Spain. Email: latorrep@unizar.es

\begin{abstract}
The circular economy is presented as the sustainable solution as opposed to the current linear model of production and resource management, whose effects impact negatively on the economic, social and environmental dimensions. Through a systematic review of the literature, this article aims to unify and to uncover the available evidence on innovation in relation to the circular economy and to determine those aspects that remain unexplored or should be studied in more depth in order to be able to continue to make progress in this field. Thus, it was found that although the circular economy is at an early stage of implementation, both its benefits and drivers as well as its challenges and barriers to implementation have already been investigated. More importantly, it was found that ecological innovations, which reduce the environmental impact of production and consumption activities, are necessary for the research of new business models and new ways of operating in supply chains that allow closing the circle and taking advantage of all the waste, such as the system of products and services, dynamic capabilities, 3D printing, the biography of the product and the software recycling. To achieve this goal, the evidence shows that it is mandatory to raise awareness of the situation, especially through marketing actions, as well as for companies, including SMEs, to be willing to act together and to align their interests.

Implications for Central European audience: The United Nations 2030 Agenda includes 17 Sustainable Development Goals (SDGs), according to which countries should implement the circular economy in order to move towards greater sustainability. In this context, European Union is key for this development, as it is one of the world's major power. This article aims to unify and uncover the available evidence on innovation in relation to the circular economy and to determine those aspects that remain unexplored or should be studied in more depth. By doing so, it will be able to continue to make progress in the framework of the circular economy, enabling the achievement of the ODS. In addition, the majority of the articles reviewed take place in Europe.
\end{abstract}

Keywords: circular economy; innovation; SDG 


\section{Introduction}

In 2015, the United Nations established 17 Sustainable Development Goals (SDGs) that were adopted by world leaders, with the aim of achieving them by 2030 . Despite the fact that each one focusses on a different aspect and, therefore, each objective has different purposes, a common idea underlies all of them: the implementation of the circular economy as the sustainable solution as opposed to the current model of production and resource management, whose effects have a negative impact on the economic, social, and environmental dimensions.

In particular, SDG 9: 'Industry, Innovation and Infrastructure' is important because economic growth, social progress, and action to combat climate change depend largely on investment in infrastructure, sustainable industrial development, and technological progress (UN, 2015). Thus, the justification for this work lies in the need to research new and innovative forms of industrial production within the framework of the circular economy that will enable the achievement of the SDG, especially number 9.

For this reason, the objective of this article is to uncover the available evidence on innovation in relation to the circular economy and to determine those aspects that remain unexplored or should be studied in more depth in order to be able to continue to make progress in this field. To this end, a systematic review of the literature has been carried out, a research method which consists of analysing and collecting the results of all the publications relating to the subject to be dealt with; in this case, on innovation and the circular economy. In this way, the available information is summarised, and a current overview of the subject in question is identified.

This paper consists of three main sections. Firstly, the methodology, which presents in a wider and more exhaustive way the sample selected for a systematic review of the literature. Secondly, the results, which include the most relevant contributions of the articles analysed, presenting the current situation of innovation and the circular economy. And finally, the conclusions, which explain the contributions of this work and the limitations of the study, as well as future lines of research related to the subject.

\section{Methodology}

In this section, the methodology used is presented.

\subsection{Sample selection}

In order to achieve the proposed objectives, a systematic review of the literature has been carried out. This research method consists of selecting and examining publications related to the subject matter of the study in order to synthesise the available evidence. It is a qualitative method widely used in academic literature whose capacity to facilitate drawing conclusions has been demonstrated. Several articles can be found confirming this from very varied subject areas because it is used for all kinds of knowledge production (Booth et al., 2016; Carayannis et al., 2021). 
Through this approach, a sample of 38 published articles on innovation and the circular economy have been identified and analysed in order to examine the published literature and establish what has been researched and what remains unexplored.

The search, screening, and selection of the sample of articles reviewed are graphically represented in Figure 1; the database consulted was Web of Science (WoS).

First, the appropriate search terms were established using the keywords' circular economy' and 'innovat", circular economy and innovation. From the main collection of Web of Science, the citation indexes 'Science Citation Index Expanded (SCI-EXPANDED) - 1900present' and 'Social Sciences Citation Index (SSCI) - 1956-present' were selected. The search yielded a total of 503 results that matched the assigned criteria.

Secondly, the available categories of Web of Science were filtered and refined with the terms 'MANAGEMENT' and 'BUSINESS'. In this way, only those documents contained in specialised magazines in these two areas of knowledge would appear. The results were then screened according to the year of publication, choosing a time period covering the last five years, namely articles published from 2016 to April 2020. The sample was reduced from 503 results to 43 .

Thirdly, the type of document was selected to be an article, and the search was screened by language, selecting only those that were written in English in order to ensure the quality of the publications.

Lastly, a total selection of 38 articles was obtained, which were carefully read and reviewed in their entirety to verify that they were within the framework of the study.

Once the 38 articles were found to fit within the framework under study, they were categorised and grouped by its main theme, one for each sub-chapter of the following section (CE paradigm, the road to CE, the importance of collaboration, eco-innovations, CE in SMEs, the importance of consumer awareness change and CE in the textile industry). However, as they are related, some articles, although not as their main research topic, also contribute to other topics.

Finally, one of the limitations of this research is that it has only followed a single methodology, the systematic review of the literature, so it would have to be combined with other methods in order to increase knowledge on the subject.

Similarly, only one database has been consulted - the Web of Science - so it would be appropriate to extend the range of the sample using other databases. 
Figure 1 | search, screening and selection of the sample

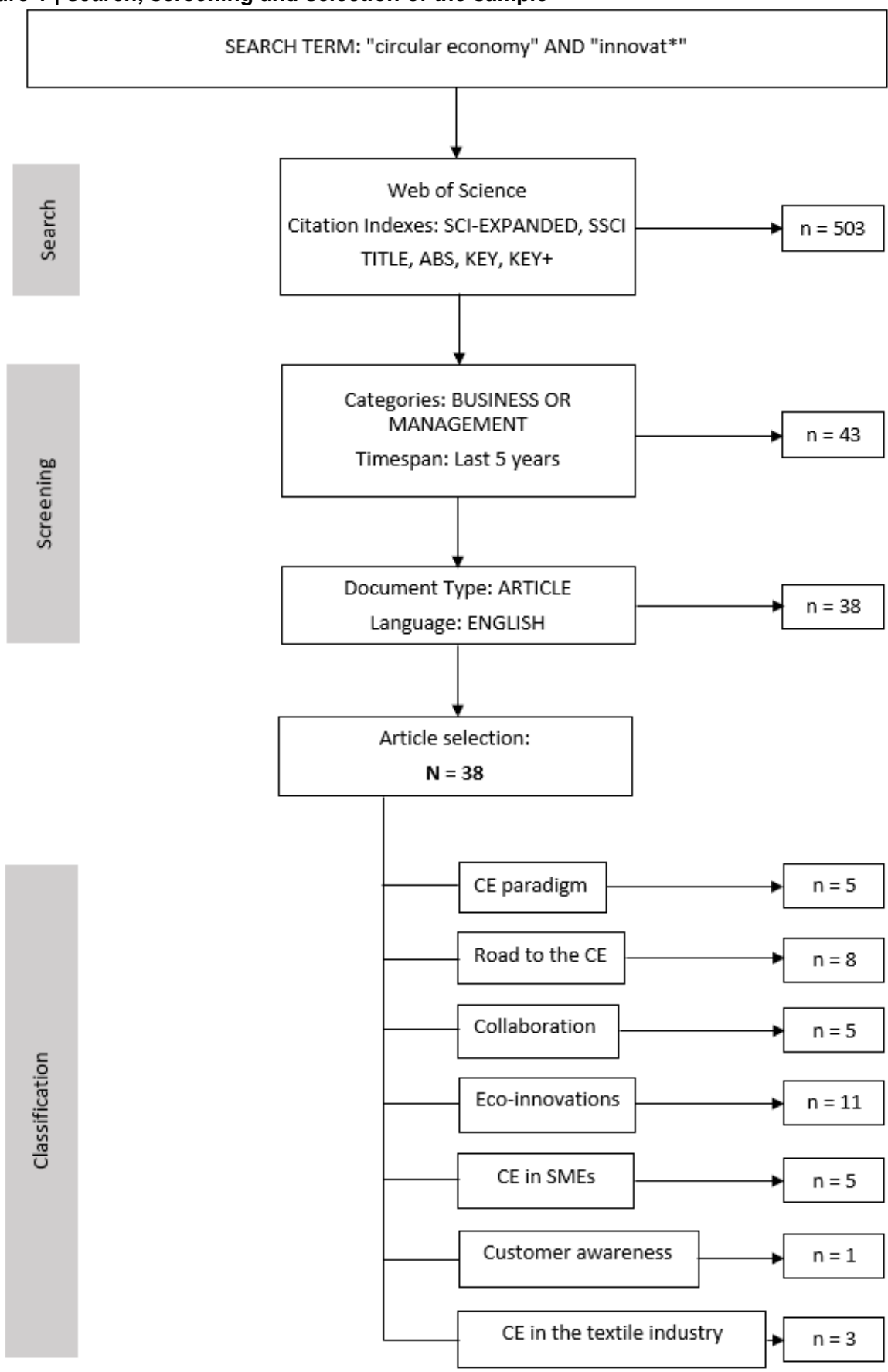

Source: authors 


\section{Results}

\subsection{The paradigm of the circular economy}

The circular economy (CE) is defined as:

An economic system based on business models that replace the end-of-life concept by reducing, reusing, recycling, and recovering materials in production or distribution and consumption processes, thus operating at the micro (products, companies, and consumers), meso (ecological industrial parks), and macro (city, region, national, and global) levels, with the aim of achieving sustainable development that involves creating an environment of quality, economic prosperity, and social equality for the benefit of current or future generations (Dey et al., 2020).

Although CE was already defined in 1990 by Pearce and Turner, it has only been in recent years that this concept has become increasingly important, not only for companies but also for society. Today, we find ourselves in a linear economy based on the intensive use of natural resources that negatively impacts the environment and produces waste and which, due to globalisation, is no longer sustainable. Some authors call the current era in which we live the Age of the Anthropocene or the Age of Humans, characterised by massive impacts on social and ecological landscapes worldwide created or influenced by human activities that have caused negative consequences. Due to the current economic structure, companies have a responsibility to address the challenges we currently face (Edgeman, 2020).

With CE, the aim is to extend the end of the product's useful life so that a company's waste or outputs become inputs for other production cycles through the processes shown in Figure 2. This process leads to the reduction of waste and the conservation of most of the value of products, raw materials, or resources within the production circuit for a longer period of time (Vuta et al., 2018), which in turn represents a new source of income. Reconceptualising waste as a resource means adopting new innovative strategies for existing supply chains (Perey et al., 2018). This leads us to adopt and search for a business excellence approach that incorporates principles of sustainability, adaptability, soundness, and innovation. Companies must identify which challenges and issues they will cover and then pool resources and align the organisation to address them (Edgeman, 2020).

The Ellen MacArthur Foundation, a charitable association whose objective is to promote the transition to CE (Volker et al., 2020), establishes five business models that characterise companies in this economy and require innovation for their implementation: circular suppliers, resource recovery, product life extension, shared platforms, and products as services (Zucchella \& Previtali, 2019). 


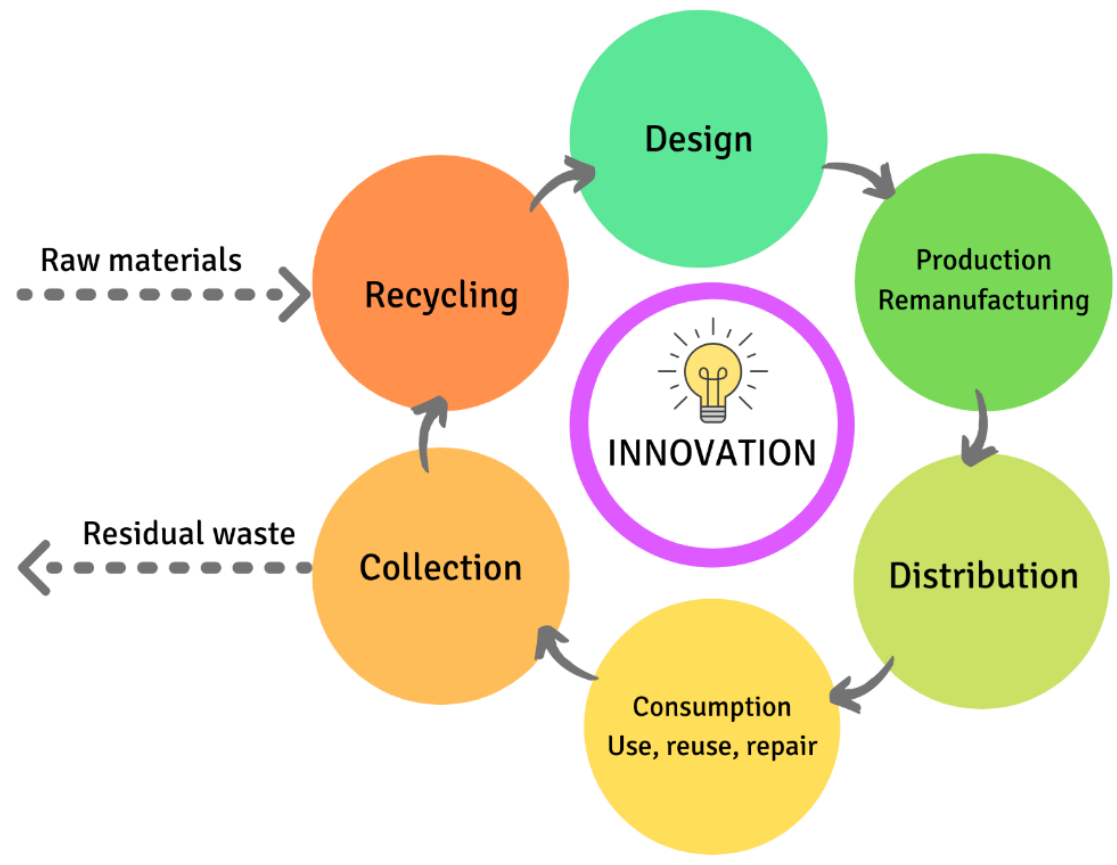

Source: own elaboration based on Volker et al. (2020)

The transition from a linear economy to a CE is envisaged by the European Commission (Vuta et al., 2018) through various communications, documents, policies, and directives, such as the Paris Agreement and the Agenda 2030 (Volker et al., 2020).

Specifically, the research carried out by Siminica et al. (2020) studied the National Green Procurement Plans adopted in Europe during the 2007-2018 period, confirming the positive impact of their establishment on economic growth and on some relevant indicators of the $\mathrm{CE}$, justifying it with a growth in the ecological GDP (relationship between economic development and the conservation of natural resources and the environment) in those countries that have implemented them.

In short, the current political context of the European Union has as its main priority intelligent, inclusive, and sustainable economic growth, as established by the European Strategy 2020. Thus, policies for sustainability and environmental protection, crucial for implementing a CE in Europe (Cainelli et al., 2020), have to be compatible with the overall objective of economic growth (Volker et al., 2020).

\subsection{The road to the circular economy}

CE has multiple benefits both for the companies that implement it and for the economic development of the country. In particular, the study by Vuta et al. (2018) proves that measures associated with circular principles have a direct and positive impact on resource productivity and, therefore, on economic growth. In fact, Sana (2014) estimates that Europe 
could save 630 billion euros per year thanks to more efficient use of resources. It should be borne in mind that increasing resource productivity also means creating more jobs. The European view has confirmed that increasing resource productivity by $30 \%$ by 2030 can lead to a growth in green GDP of almost 1\%. In the European Union, the importance of research and innovation in the transition process from a linear economy to a CE has been strengthened while applying the principles of sustainable development.

At a micro level, the implementation of circular business models would lead to savings in manufacturing costs, the differentiation potential, improved customer relations, increased marginal profits, reduced environmental impact, and increased brand protection through CE derived patents (Linder \& Williander, 2017). The results of the case study conducted by Hopkinson et al. (2018), in which a company implemented a circular business model, confirm the benefits of CE.

The CE also has a series of conductors that facilitate its application. Frishammar and Parida (2019) propose a guide through four phases for transforming from a linear to a circular business model for dominant companies, which is a challenge as they have to change the way they create, deliver, and capture product value for customers. These companies must make a change towards sustainability, as even at a moderate level, they can have a significant environmental effect due to their high market share.

Among the drivers propelling organisations to contribute to business sustainability is the threat of new competitors, new policies and legislation, the intrinsic motivation of the company, social pressure, price instability, or a combination of all of these factors (Frishammar \& Parida, 2019). Cainelli et al. (2020), on the other hand, establish that environmental regulations and market demand for green products drive the adoption of resource-efficient and CE-related technologies.

The case study of Zucchella and Previtali (2019) presents a model of implementation of CE that takes place in the agricultural sector and contains key blocks of successful application of CE such as innovations in products, processes, and business models; the range of actors committed to the circular principles; and the key role of the orchestrator to pursue and share a joint vision and cause it to materialise into an ecosystem business model.

However, the phases of transition to CE are incompatible with some characteristics of the linear economy, leading to several external barriers and challenges in implementing circularity (Hopkinson et al., 2018).

Linder and Williander (2017) conducted a case study of a small company that developed a circular business model and identified ten types of challenges and/or constraints (see Table 1). 
Table 1 | Challenges and limitations of CE identified by Linder and Williander (2017).

CHALLENGE AND/OR LIMITATION

Clients

Technology experts

Return of the flow

Product classification

Decline of some of the company's products

Vulnerability to fashion

Fixed capital risk

Increased operational risk

Policies and legislation

Partners

\section{WHY IS IT A CHALLENGE AND/OR LIMITATION?}

Not everyone is environmentally aware.

The best way to restore the product to its original condition or a better one.

Not all products return to the supply chain.

Not all can be reused.

Possible decrease in sales if the new product with a long lifecycle period reduces the sales of the previous ones.

Inability to respond to changes in product design.

If the product is rented instead of sold, a financial risk is transferred from the customer to the producer.

Consequences of increased responsibility.

Lack of regulation, policies, and supporting legislation.

Your business models must be compatible with the main company.

Source: own elaboration based on Linder and Williander (2017)

These authors also established that while linear models can be considered successful or unsuccessful according to the number of products sold on a given occasion, circular models are not validated until some circular products have been successfully sold. In other words, validating a circular model always has a higher business risk than validating the corresponding linear model.

Hopkinson et al. (2018) named other barriers such as high transportation and component costs, bans on certain imports, and foreign regulatory restrictions and tariffs. Frishammar and Parida (2019) established that the main difficulty that firms may encounter is uncertainty, as less information is available on circular business models and their trajectories. Moreover, most of the elements that influence the firm are either totally or partially out of its control. The organisation can plan a strategy and take appropriate action but not control them directly. Cainelli et al. (2020) also confirmed that R\&D actions have a weak or even negative effect in many cases because they are very generic and have a low commitment to improving the adoption of environmental innovations. In their study, Perey et al., (2018) highlighted that customers consider reused products to be of lower quality than 
new products. They also determined that the main impediment faced by organisations to reestablish waste is institutional.

The World Economic Forum also identified that the geographical dispersion of firms and suppliers, the complexity and increase in materials, and the blockage in the linear economic model make the adoption of CE difficult (Spring \& Araujo, 2017).

The article published by Vuta et al. (2018) could not confirm a positive relationship between resource productivity and the growth rate of real ecological GDP because we are still at an early stage of implementing the measures and continue to use raw materials whose exploitation hurts the environment. The results also confirm the negative impact that environmental taxes have on economic growth.

On the other hand, a recurrent challenge in the generation and management of resources is knowing how much waste is generated and, consequently, the main waste flows that need to be regulated. This question is further exacerbated by how to measure waste, as this will depend on whether it is counted by weight, by critical raw materials, or by hazardous materials (Volker et al., 2020).

In his study, Sharma et al., (2019) classified the different challenges in the food industry.

On the other hand, all the above-mentioned improvement actions may involve unintended negative environmental consequences, such as increased consumption due to energy efficiency and material improvements that reduce costs or a new product launched on the market. This can lead to the so-called 'consumption rebound effect', which could be mitigated by increasing consumption costs (Laurenti et al., 2016).

Zwiers et al. (2020) investigated circular literacy, the knowledge-based ability to implement CE models to foster sustainable development. This study proposes that a specific type of knowledge is needed to fully utilise the transformative potential of CE as a sustainable way of producing and consuming and as a solution to the various difficulties of global political relations and issues of an uncertain future. In this sense, the results of the study by Horvath et al. (2019) point out that the phenomenon of CE is the result of fighting for market competitiveness, rather than making efforts for its sustainable development, in particular, they argue that CE seems to be an economic rather than an environmental concern.

In conclusion, previous literature shows that although CE has many challenges and barriers to its implementation, it also has benefits and drivers that can be overcome and, in fact, overtake its limitations.

\subsection{The importance of collaboration and alignment of interests}

CE implementation involves complexity and interdependence between the actors that no company can achieve alone, so joint action by an entire ecosystem is necessary (Parida et al., 2019). The study by Hvass and Pedersen (2019) on the textile industry supports this argument. Gregory et al. (2020) also concluded that the transition to CE depends on the recognition by stakeholders that no single actor can address the core issue alone. Cooperation is necessary to create value in the context of the business ecosystem. In CE, information exchange between organisations in various business ecosystems is crucial (Rajala et al., 2018). 
This requires an actor capable of assuming an integrative role (Rajala et al., 2018), called an orchestrator. These leaders must be large companies (Parida et al., 2019), share a common vision, build relationships based on trust, commit resources, and possess transformational leadership in key decision making (Zucchella \& Previtali, 2019). Zhu et al. (2017) also state that larger companies are more likely to implement CE because they gain more economic and social benefits through their sustainable practices, are typically targeted by environmental regulations, tend to have more resources, and may risk investing in such practices.

In the study carried out by Parida et al. (2019), two stages are established through which the orchestration of the environment can be achieved with the help of three mechanisms. They conclude that the problems of the circular business model transcend the value chain relationships, so it is necessary to align the interests and incentives of all stakeholders concerning the company, creating a scenario that can cause conflicts and opportunistic behaviour.

For their part, Gregory et al. (2020) are studying the possibility of adopting industrial symbiosis (a group of companies that promote ecological innovations) for the disposal of industrial waste, reusing the waste of one company as an input in the production of another. This would allow more resources and capacities to be shared, with a positive effect on ecoinnovations.

The study by Zucchella and Previtali (2019) establishes a step-by-step procedure for implementing a circular business model supported by the orchestrator. It introduces the need for circular business models to be designed, maintaining the dimensions of scalability (the possibility of growth of the model) and replicability (the possibility of transferring the original model to other contexts). This study shows that carrying out a circular resource model is beneficial for sustainability and the company's economic profits.

Additionally, Jakhar et al. (2019) examine why different companies under similar stakeholder pressures have adopted different circular practices. The reason is that the performance of such pressures depends on the innovative capabilities of the firm. There are two types: exploratory ones, where firms are synchronised to adopt rapid change and find it easier to adopt these practices to achieve a sustainable competitive advantage, and exploitative ones, which are opposed to circular needs. The results show that stakeholders negatively influence innovative exploitative capacities because there are no incentives to follow CE. For their part, Scarpellini et al. (2020) and Zhu et al. (2017) establish that pressure from business stakeholders positively affects companies' environmental proactivity beyond regulatory requirements.

Finally, it is important to pay attention to the Maker Movement. This movement raises awareness of the importance of collaboration and participation in achieving CE, combining traditional processing with digital manufacturing technologies and tools, such as 3D printing. The makers (those who participate in this movement) share their ideas and solutions in collaborative workspaces, always under the premise of circular principles, especially repair and recycling. Furthermore, they return production to the cities where consumption occurs, which generates social, economic, and environmental benefits (Unterfrauner et al., 2019). 
However, there are also certain challenges in this movement that have to be considered, such as, for example, that most of the filaments for 3D printers are not recycled, or that the material supply chain of manufacturers is not transparent, so they do not know exactly how and under what conditions raw materials are produced and transported to local production spaces (Unterfrauner et al., 2019).

In short, it can be obvious that collaboration is essential when it comes to implementing CE at a firm level. The alignment of interests, especially through an orchestrator, reinforces the benefits of circularity and allows any difficulties to be overcome.

\subsection{Reinventing the system through ecological innovations}

Eco-innovations (EI), defined as innovations that reduce the environmental impact of production and consumption activities, play a very important role in the search for more sustainable societies (Kiefer et al., 2019) because they transfer individual technologies (Scarpellini et al., 2020). Els require more cooperation than other innovations, as they are characterised by new technologies that require more external sources of knowledge and information than innovation in general (Kiefer et al., 2019).

The study carried out by Demirel and Danisman (2019) identifies two main El pathways: cleaner production and eco-design of products. They also establish that the positive impact of innovations on companies is conditioned by their structure, characteristics, specific innovation strategies, and the industry context.

Scarpellini et al. (2020) considered in their study four groups of El related to CE: investments in El, eco-design, investment, and improvement of innovative and renewable equipment or processes for energy efficiency, and investments in R\&D. The results indicate that the impact of informal, as opposed to formal, environmental management tools goes beyond the level of circular El and indirectly affects the company's circular activity, helping to strengthen the circular material circuit. They also identified the growing importance of new tools capable of supporting new El developments, such as environmental management accounting, human environmental resources, and corporate governance.

Kiefer et al. (2019) found that organisations when making decisions regarding EI, do not take internal factors into account as much as external ones. They analyse the resources, competencies, and dynamic capacities as determinants of the different types of El, classifying them according to the degree of radicality, resulting in systemic Els, which underlie institutional change and are more radical, on the one hand, and radical Els, on the other. They also expose several drivers and barriers to the implementation of El.

Scarpellini et al. (2020) conclude that companies that have previously demonstrated Elrelated skills can be put into practice in new innovative circular business models and could more easily implement CE-related activities.

On the other hand, several organisations that implemented circular principles from the Perey et al. case study (2018) pursued disruptive innovation, reinvented their business models and, in doing so, changed their practices in the industry.

The following are several in-depth Els through which progress can be made in achieving the circular objectives. 
The first is the system of products and services, an innovative business model. With the CE paradigm, probably the most difficult sustainability challenge in the capitalist economy is separating economic growth from consumption (Laurenti et al., 2016). To address this, two main types of innovative models are used.

- First, the user-oriented business model, where the company owner provides a product under rental or lease contracts but retains ownership.

- Second, the results-oriented business model, where the lead company provides the customer with a predefined outcome (Frishammar \& Parida, 2019).

These are encompassed within the so-called system of products and services by which a change in the business model is proposed, moving from offering a manufactured product where the profit depends on the number of units sold to offering a combination of products and services that meet the needs of the consumer, where the profit also depends on the service units delivered (Linder \& Williander, 2017). Spring and Araujo (2017) also studied this innovative idea in their article from the perspective of servicing (service-based growth).

In the second place, there are the dynamic capabilities in order to achieve sustainable competitive advantage. Several authors analyse this concept, implying a sustainable competitive advantage (Scarpellini et al., 2020). These include capacities for detecting needs, taking advantage of opportunities, and reconfiguring the system based on the idea of micro-foundations made up of different skills, processes, and business activities. They are also envisaged in remanufacturing, which is a form of sustainable manufacturing by reusing the remaining value in old products instead of disposing of them in landfills. In this case, they are called dynamic remanufacturing capabilities (DRC). They are described as the ability to optimise and apply variations to production lines by altering the manufacturing process times of individual components. This requires, on the one hand, systems of flexibility that allow modifications to the structure according to the volume of products recovered and the requests of the end customers; and, on the other hand, control systems that make it possible to supervise operations cost-effectively and reduce the associated risks (Bag et al., 2019).

The study by Khan et al. (2020) confirms that companies using several micro-foundations could successfully identify and respond to circular opportunities. This study shows that dynamic capabilities make it easier for the company to integrate, create, and reconfigure resources for sustainability in this dynamic business environment.

The article by Scarpellini et al. (2020) identified a positive relationship between the circular scope of companies and their environmental capabilities, consolidating the concept that the use of environmental management accounting tools can be related to the management of CE in companies.

To help companies build a sustainable competitive advantage, Prieto-Sandoval et al. (2019) also looked at dynamic capabilities, which will depend on whether the objective is to make sense of and shape opportunities and threats, achieve size opportunities, or maintain competitiveness.

On the other hand, Kalverkamp (2018) analysed remanufacturing concerning the circular flow of products through used components or reverse logistics in the automotive industry. Several obstacles were found, the solution for which is proposed to be e-procurement. 
A third $\mathrm{El}$ is the 3D printing, which encourages recycling through its process. Despeisse et al. (2017) and Garmulewicz et al. (2018) study the role of 3D printing in the implementation of CE. Thus, 3D printing is considered an emerging disruptive technology capable of enabling and facilitating the transition to CE by adding new capabilities and changing the underlying economy of several manufacturing sectors (Garmulewicz et al., 2018). It facilitates recycling through a product design that allows for longer product life and establishes a local supply chain, taking advantage of economies of scope rather than economies of scale, resulting in significant cost reductions (Despeisse et al., 2017).

However, there are several difficulties that could be overcome in the short or medium term. These include economic, technological, social, organisational, and legislative barriers. The most important of these are the current low quality or defects in 3D printed products, for which greater technological innovation is required; and the low economic attractiveness of storing plastics due to regulation, for which the value generated by the new product made from recycled plastics would have to be increased (Garmulewicz et al., 2018).

In the fourth place, connectivity between objects is studied through the product's biography and mechanisms. The implementation of $\mathrm{CE}$ requires technological changes and institutional innovation to enable products to be accessible and shared or sold. This introduces product biography to study the relationships of products with services and other objects and in the different processes throughout their lifespan. This approach suggests seeing them as a set of trajectories with changing qualifications rather than a stable and productive conceptualisation of the object. Products are repaired, reconditioned, improved, manipulated, dismantled, reassembled, and discarded (Spring \& Araujo, 2017).

The elaboration of these biographies can be achieved using the intelligent and connected products of the Internet of Things, since it implies connectivity between them and storage of their information and allows the provision of a wide range of services on the product, including, for example, its maintenance. In short, those companies and CE networks that can guarantee the origin of materials and components in reverse cycles of reuse, reworking, and recycling will obtain a competitive advantage over those who cannot understand the biographies of their products (Spring \& Araujo, 2017).

Programmed intelligence, which turns products into active nodes of new value creation systems, helps maintain the balance between the company and the environment. It provides objects with information about themselves. Innovative companies have to develop new practices that allow them to share information and use data related to circular materials and products. To this end, it is necessary to extend the life cycle of goods and reconsider their ownership to expand their consumption. Key to the achievement of these objectives is information on the goods, which results in intelligent goods. Industries must be connected for the reciprocal transmission of knowledge, using an increased trust, improved collaborative methods, and reduced opportunism among stakeholders. They conclude that, in general, sharing information is more important than simply having it (Rajala et al., 2018).

Finally, a fifth innovation tries to implement the CE in software, that is, far beyond the hardware components. In the electronics industry, circular practices must be established not only for hardware components but also for software products. The owner of a device does not have the same rights and freedoms about a tangible good because, for the use of software, a licence for use is acquired only for the period of its ownership. This is a 
limitation for the reuse or repair of the device and its software. The developers of these programs must configure digital rights management in such a way that it does not affect certain consumer behaviour after the purchase of the product and that it does not restrict the use of an old version of the device, thus extending the life of the software (Onete et al., 2018).

In this sense, Onete et al. (2018) studied a group of young people to find out about their trends and behaviour with the use of electronic equipment and the software installed on them. It was determined that when they sell their mobiles or computers, they eliminate the software installed on them, making it impossible to reuse them.

All in all, IE will be the means through which the implementation of CE will be possible in the industries. Specifically, the system of products and services, dynamic capabilities, 3D printing, the biography of the product and the software recycling seem to be the main El for which the CE will be supported.

\subsection{The circular economy in SMEs and other enterprises}

SMEs account for around $90 \%$ of the world's business, employ $50-60 \%$ of the world's population and are responsible for over $70 \%$ of industrial pollution. These facts show the importance of achieving sustainability in SMEs in order to make the entire ecosystem sustainable, but adhering to social and economic objectives makes it difficult for them to maintain their competitiveness, as many social and environmental projects are costintensive (Dey et al., 2020), in addition to receiving limited government support (PrietoSandoval et al., 2019). In their study, Dey et al. (2020) establish many barriers, benefits, and opportunities for SMEs in adopting CE.

Dey et al. (2020) also indicated that industry could achieve CE through five phases (take, make, distribute, use, and recover), namely by converting linear business processes (take, make, and distribute) into circulars (p.2). The article published by Prieto-Sandoval et al. (2019) identifies a series of strategies, internal factors, resources, capacities, and competencies in each of the five phases which can favour the circular paradigm in SMEs, intending to help them to choose which combination of the factors mentioned should be applied in order to advance their environmental management.

Demirel and Danisman (2019) also analysed SMEs in a circular context. They stressed the importance of eco-design as the only EI that positively impacts the growth of this type of company, as it saves energy and material costs due to more eco-efficient design. However, they stated that this would require exploring alternative funding sources, such as government subsidies, as limited external funding fails to drive business growth.

In the biotechnology sector, where intellectual capital and knowledge management are of great importance, Nedelea et al. (2018) determine that SMEs must base their competitive advantages on innovation and on the management of the intelligence of the available knowledge, for which human capital is key, and they must be motivated and trained through the organisational culture. Horvath et al. (2019) state that the exchange of knowledge in the biotechnology industry is essential, pointing out innovation and collaboration, the use of information technologies, and a change in consumer perception as key aspects of the transition towards circular models. Companies with intensive use of advanced information technologies will have a definite market advantage in the future. 
On the other hand, the article by Zhu et al. (2017) studies certain companies in China and Japan, concluding that depending on the size and type of company and the development of regulations by the country's government, there are differences in the awareness of environmental regulations and policies and the implementation of green supply chain management practices, as well as different effects of regulations on the implementation of green supply chain management. In China, the implementation of CE is based on three pillars: ecological modernisation, industrial ecology, and environmentally friendly production (Vuta et al., 2018).

In conclusion, SMEs also have to be taken into account when implementing CE due to the level of employment they provide, the number they are and the amount of pollution they produce.

\subsection{The need for a change in consumer awareness}

As we have seen, consumers play a significant role in the implementation of CE. They are increasingly paying attention to where goods come from and how companies operate (Rajala et al., 2018). For this reason, companies are forced to move towards the concept of CE and sustainability in their business models (Sharma et al., 2019). The Horvath et al. study (2019) results indicate that customer orientation forces companies to be aware of different consumer behaviour patterns.

In this sense, ecological awareness is key to decision-making on sustainable consumption behaviour in customers. Unterfrauner et al. (2019) point out that consumers are willing to pay a premium for sustainable products, but they lack sufficient and reliable data. They add that information related to sustainability should be displayed systematically and transparently to promote the purchase of greener products. Thus, Hopkinson et al. (2018) establish that marketing is capable of significantly influencing consumer behaviour. Consumers have been educated under the premise that what is new is best. In their article, Laurenti et al. (2016) highlight the importance that advertising and media have had about programmed obsolescence and perceived obsolescence, convincing people to throw away goods that are still perfectly useful. However, branding and marketing can re-educate consumers about the value of products manufactured in a CE process (Hopkinson et al., 2018).

With the maker movement and 3D printing, a new concept is introduced, 'prosumerism', which crosses the line between producers and consumers by emphasising the importance of culture, education, and awareness of circularity (Despeisse et al., 2017; Unterfrauner et al., 2019).

To sum up, consumers have a crucial role to play in the implementation of CE. For this reason, change must start with them to force companies to adopt more sustainable solutions in their products and services.

\subsection{The textile industry: From fast fashion to slow fashion}

The textile industry deserves special attention as it is one of the most polluting industries in the world (Vehmas et al., 2018). The increase in the volume of garments that end up in landfills or incinerated is one of the major challenges of CE within fashion, derived from the main problem of this industry: the fast fashion phenomenon or disposable fashion, where 
the fast production and consumption of clothes has created a perception among consumers that clothes are disposable (Hvass \& Pedersen, 2019). Using textile waste as a resource can be achieved with CE by recycling the waste (Sandvik \& Stubbs, 2019). Vehmas et al. (2018) showed in their study that consumers are willing to recycle their garments to produce new ones. Thus, Hvass and Pedersen (2019) concluded that CE in fashion could only become a reality when well-functioning garment collection systems and efficient sorting procedures are in place.

The article published by Todeschini et al. (2017) identifies many drivers, challenges and opportunities as an alternative to the fast fashion paradigm. Among the drivers, they identified CE, veganism, the adoption of Corporate Social Responsibility (CSR) through fair trade and free production, shared economy and collaborative consumption, technological innovation, and a change in consumer awareness.

However, several challenges hinder the development of sustainability for the industry. Firstly, there are technical challenges in the product design phase strategy. Secondly, there is a difficulty in changing the education of consumers, who need to be convinced of the benefits of circularity. Thirdly, there is a need for a change in customer perceptions of the company's activities and intentions towards sustainability. And fourthly, the difficulty of aligning values along the supply chain is also a challenge (Todeschini et al., 2017).

Sandvik and Stubbs (2019) also analysed a set of facilitators and drivers of the circular supply chain and inhibitors that make it difficult to implement these principles. They stress that introducing CE requires the adoption of systemic changes and technological development, which, by allowing digitalisation in industry, would create transparency about the materials used in products and develop aspects of traceability and automation concerning classification processes.

On the other hand, the study carried out by Hvass and Pedersen (2019) supports the argument that a single company cannot implement and operate a circular business model by itself, having to modify all the elements and reconstruct the existing value chain so that the value of the product extends beyond its consumption.

Customers are essential in the shift towards CE. In the textile industry, consumers must return their products so that companies can reuse and recycle them (Hvass \& Pedersen, 2019). The return of clothes must be promoted, and consumer behaviour changed to ensure the flow of materials (Sandvik \& Stubbs, 2019).

The role of communications in the textile industry was also analysed, indicating that marketing is key to persuading society of the relevance of sustainable consumption. In addition, the production process must be transparent, as it increases consumer confidence (Vehmas et al., 2018).

In short, the implementation of CE in the textile industry, one of the most polluting industries globally, is essential for further progress. This requires, above all, a green conscience on behalf of consumers.

\section{Conclusions}

In conclusion, CE is presented as the solution to the environmental problem that has been facing humanity for several years now. Although it is still at a very early stage of 
implementation, its benefits and drivers have already been investigated, and its challenges and barriers to implementation. Proof of this is that the European Union has already started to adopt sustainable growth policies that promote CE.

The aim was to ascertain the available evidence on innovation concerning CE. The results have shown that this is a key aspect for achieving the circular objectives. Thus, it has been shown how collaboration and alignment of interests between all companies, especially SMEs, and all sectors, especially the textile industry, can help achieve this sustainable development. The EI is necessary to leave behind the current linear economic model, committing to new business models and new ways of operating in the supply chains that allow the circle to be closed and all the waste to be taken advantage of. All the proposals that have been studied, i.e. the system of products and services, dynamic capabilities, 3D printing, the biography of the product and the software recycling, have already been put into practice to a greater or lesser extent, largely because companies and consumers are increasingly aware of the importance of being part of the fight against climate change.

The aim was also to identify those aspects that remain unexplored or studied further to make further progress in this area. In general, future research could validate the articles analysed by extending data over time, as well as through an expansion in the scope, gathering information on the whole industry, since, as we have seen, the implementation of CE is needed throughout the business ecosystem. Furthermore, its application should also be verified in other continents whose countries are underdeveloped since most studies have been undertaken in Europe.

In particular, aspects that require further exploration are the possibilities for innovative design of circular products to achieve greater adaptability for the unknown future; modifying the design of the business model to reduce the risk in product and service system offerings based on retained ownership; exploring options for designers to consider circular principles when using 3D printing; adopting a more dynamic analysis of the relationship between circular green innovations and business performance, when such innovations have been adopted, and sufficient data is available, and studying all phases of a product's life cycle to develop and implement an integrated and economically viable business model that aims to transition from the circular system.

In addition, studies on the impact that the dynamics of trade with recycling and secondary raw materials may have on some macroeconomic variables or the impact of CE on social, political, economic, and technical aspects would also be interesting to clarify the path towards CE.

Finally, the 2035 strategy is a major strategic plan of action with important academic, management and public implications for all actors involved in innovation systems that aim to reduce the amount of municipal waste deposited in landfills to $10 \%$ or less of municipal waste generated in a given year by 2035 (Zero Waste Europe, 2020). In this sense, future research work may try to analyse the impact of this strategy in different industrial sectors, at a firm level and at a country-level, and the environmental and economic consequences of their implementation. It would also be interesting to study the impact of the required changes in production processes and environmental policies. 


\section{References}

Bag, S., Gupta, S., \& Foropon, C. (2019). Examining the role of dynamic remanufacturing capability on supply chain resilience in circular economy. Management Decision, 57(4), 863-885.

Booth, A., Sutton, A., \& Papaioannou, D. (2016), Systematic approaches to a successful literature review, Sage, London.

Cainelli, G., D'Amato, A., \& Mazzanti, M. (2020). Resource efficient eco-innovations for a circular economy: Evidence from EU firms. Research Policy, 49(10), 103827.

Carayannis, E. G., Ferreira, J. J. M., \& Fernandes, C. (2021). A prospective retrospective: conceptual mapping of the intellectual structure and research trends of knowledge management over the last 25 years. Journal of Knowledge Management, Ahead-of-print. https://doi.org/10.1108/JKM07-2020-0581.

Comisión Europea. (2018). Comunicación de la comisión al parlamento europeo, al consejo, al comité económico y social europeo y al comité de las regiones sobre un marco de seguimiento para la economía circular. Retrieved in 2020, from https://eur-lex.europa.eu/legalcontent/ES/TXT/PDF/?uri=CELEX:52018DC0029\&from=ES

Demirel, P., \& Danisman, G. O. (2019). Eco-innovation and firm growth in the circular economy: Evidence from European small- and medium-sized enterprises. Business Strategy and The Environment, 28(8), 1608-1618.

Despeisse, M., Baumers, M., Brown, P., Charnley, F., Ford, S. J., Garmulewicz, A., Knowles, S., Minshall, T. H. W., Mortara, L., Reed-Tscochas, F. P., \& Rowley, J. (2017). Unlocking value for a circular economy through 3D printing: A research agenda. Technological Forecasting and Social Change, 115, 75-84.

Dey, P. K., Malesios, C., De, D., Budhwar, P., Chowdhury, S., \& Cheffi, W. (2020). Circular economy to enhance sustainability of small and medium-sized enterprises. Business Strategy and the Environment, 29(6), 2145-2169.

Edgeman, R. (2020). Urgent evolution: excellence and wicked Anthropocene Age challenges. Total Quality Management \& Business Excellence, 31(5-6), 469-482.

Frishammar, J., \& Parida, V. (2019). Circular Business Model Transformation: A Roadmap for Incumbent Firms. California Management Review, 61(2), 5-29.

Garmulewicz, A., Holweg, M., Veldhuis, H., \& Yang, A. (2018). Disruptive Technology as an Enabler of the Circular Economy: What Potential Does 3D Printing Hold? California Management Review, 60(3), 112-132.

Gregory, A. J., Atkins, J. P., Midgley, G., \& Hodgson, A. M. (2020). Stakeholder identification and engagement in problem structuring interventions. European Journal Of Operational Research, 283(1), 321-340.

Hopkinson, P., Zils, M., Hawkins, P., \& Roper, S. (2018). Managing a Complex Global Circular Economy Business Model: Opportunities and Challenges. California Management Review, 60(3), 71-94.

Horvath, B., Khazami, N., Ymeri, P., \& Fogarassy, C. (2019). Investigating the Current Business Model Innovation Trends in The Biotechnology Industry. Journal of Business Economics and Management, 20(1), 63-85.

Hu, Q., \& Hughes, M. (2020). Radical innovation in family firms: a systematic analysis and research agenda. International Journal of Entrepreneurial Behavior \& Research, 26(6), 1199-1234. 
Hvass, K. K., \& Pedersen, E. R. (2019). Toward circular economy of fashion Experiences from a brand's product take-back initiative. Journal of Fashion Marketing And Management, 23(3), 345-365.

Jakhar, S. K., Mangla, S. K., Luthra, S., \& Kusi-Sarpong, S. (2019). When stakeholder pressure drives the circular economy Measuring the mediating role of innovation capabilities. Management Decision, 57(4), 904-920.

Kalverkamp, M. (2018). Hidden potentials in open-loop supply chains for remanufacturing. International Journal of Logistics Management, 29(4), 1125-1146.

Khan, O., Daddi, T., \& Iraldo, F. (2020). Microfoundations of dynamic capabilities: Insights from circular economy business cases. Business Strategy and The Environment, 29(3), 1479-1493.

Kiefer, C. P., Del Rio Gonzalez, P., \& Carrillo-Hermosilla, J. (2019). Drivers and barriers of ecoinnovation types for sustainable transitions: A quantitative perspective. Business Strategy and The Environment, 28(1), 155-172.

Laurenti, R., Singh, J., Sinha, R., Potting, J., \& Frostell, B. (2016). Unintended Environmental Consequences of Improvement Actions: A Qualitative Analysis of Systems' Structure and Behavior. Systems Research and Behavioral Science, 33(3), 381-399.

Linder, M., \& Williander, M. (2017). Circular Business Model Innovation: Inherent Uncertainties. Business Strategy and The Environment, 26(2), 182-196.

Nedelea, A.-M., Mironiuc, M., Huian, M. C., Birsan, M., \& Bedrule-Grigoruta, M. V. (2018). Modeled interdependencies between intellectual capital, circular economy and economic growth in the context of bioeconomy. Amfiteatru Economic, 20(49), 616-630.

Onete, C. B., Albastroiu, I., \& Dina, R. (2018). Reuse of electronic equipment and software installed on them - an exploratory analysis in the context of circular economy. Amfiteatru Economic, 20(48), 325-339.

Parida, V., Burstrom, T., Visnjic, I., \& Wincent, J. (2019). Orchestrating industrial ecosystem in circular economy: A two-stage transformation model for large manufacturing companies. Journal of Business Research, 101, 715-725.

Perey, R., Benn, S., Agarwal, R., \& Edwards, M. (2018). The place of waste: Changing business value for the circular economy. Business Strategy and The Environment, 27(5), 631-642.

Prieto-Sandoval, V., Jaca, C., Santos, J., Baumgartner, R. J., \& Ormazabal, M. (2019). Key strategies, resources, and capabilities for implementing. Corporate Social Responsibility And Environmental Management, 26(6), 1473-1484.

Rajala, R., Hakanen, E., Mattila, J., Seppala, T., \& Westerlund, M. (2018). How Do Intelligent Goods Shape Closed-Loop Systems? California Management Review, 60(3), 20-44.

Sana, A. (2014). Enhancing water resources and coastal engineering curricula using visual basic programs in MS-Excel. In InCIEC 2013 (pp. 323-330). Springer, Singapore.

Sandvik, I. M., \& Stubbs, W. (2019). Circular fashion supply chain through textile-to-textile recycling. Journal Of Fashion Marketing And Management, 23(3), 366-381.

Scarpellini, S., Marin-Vinuesa, L. M., Aranda-Uson, A., \& Portillo-Tarragona, P. (2020). Dynamic capabilities and environmental accounting for the circular economy in businesses. Sustainability Accounting Management and Policy Journal, 11(7), 1129-1158.

Scarpellini, S., Valero-Gil, J., Moneva, J. M., \& Andreaus, M. (2020). Environmental management capabilities for a "circular eco-innovation". Business Strategy and the Environment, 29(5), 1850-1864. 
Sharma, Y. K., Mangla, S. K., Patil, P. P., \& Liu, S. (2019). When challenges impede the process for circular economy-driven sustainability practices in food supply chain. Management Decision, 57(4), $36 \mathrm{p}$.

Siminica, M., Avram, M., Popescu, L., \& Avram, R. L. (2020). The Adoption of National Green Procurement Plans from The Perspective of Circular Economy. Amfiteatru Economic, 22(53), 15-27.

Spring, M., \& Araujo, L. (2017). Product biographies in servitisation and the circular economy. Industrial Marketing Management, 60, 126-137.

Todeschini, B. V., Cortimiglia, M. N., Callegaro-de-Menezes, D., \& Ghezzi, A. (2017). Innovative and sustainable business models in the fashion industry: Entrepreneurial drivers, opportunities, and challenges. Business Horizons, 60(6), 759-770.

UN. (2015). Sustainable Development Goals. From United Nations.

Unterfrauner, E., Shao, J., Hofer, M., \& Fabian, C. M. (2019). The environmental value and impact of the Maker Movement-Insights from a cross-case analysis of European maker initiatives. Business Strategy and The Environment, 28(8), 1518-1533.

Vehmas, K., Raudaskoski, A., Heikkilae, P., Harlin, A., \& Mensonen, A. (2018). Consumer attitudes and communication in circular fashion. Journal of Fashion Marketing And Management, 22(3), 286-300.

Volker, T., Kovacic, Z., \& Strand, R. (2020). Indicator development as a site of collective imagination? The case of European Commission policies on the circular economy. Culture and Organization, 26(2), 103-120.

Vuta, M., Vuta, M., Enciu, A., \& Cioaca, S.-I. (2018). Assessment Of The Circular Economy's Impact In The EU. Amfiteatru Economic, 20(48), 248-261.

Zero Waste Europe. (2020). El nuevo objetivo $10 \%$ a vertedero puede ir en contra de la economía circular. Agnese Marcon. Retrieved in 2021, from https://zerowasteeurope.eu/2020/03/the-10landfill-target-works-against-the-circular-economy/

Zhu, Q., Qu, Y., Yong, G., \& Fujita, T. (2017). A Comparison of Regulatory Awareness and Green Supply Chain Management Practices Among Chinese and Japanese Manufacturers. Business Strategy and The Environment, 26(1), 18-30.

Zucchella, A., \& Previtali, P. (2019). Circular business models for sustainable development: A "waste is food" restorative ecosystem. Business Strategy and The Environment, 28(2), 274-285.

Zwiers, J., Jaeger-Erben, M., \& Hofmann, F. (2020). Circular literacy. A knowledge-based approach to the circular economy. Culture and Organization, 26(2), 121-141.

The research article passed the review process. | Received: February 3, 2021; Revised: March 25, 2021; Accepted: April 22, 2021; Pre-published online: July 30, 2021; Published in the regular issue: March 16, 2022. 